\title{
Endoscopic treatment of recurrent sigmoid volvulus with colopexy assisted by T-fasteners and colostomy
}

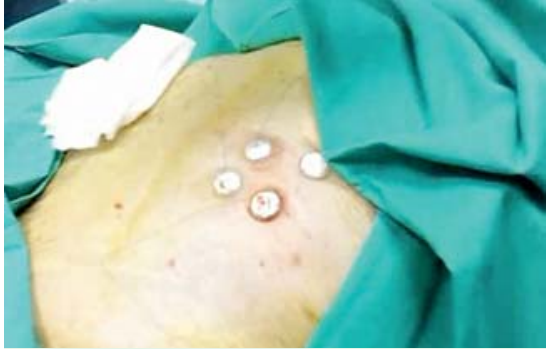

Fig. 1 T-fasteners with the suture locks closed at the abdominal wall.

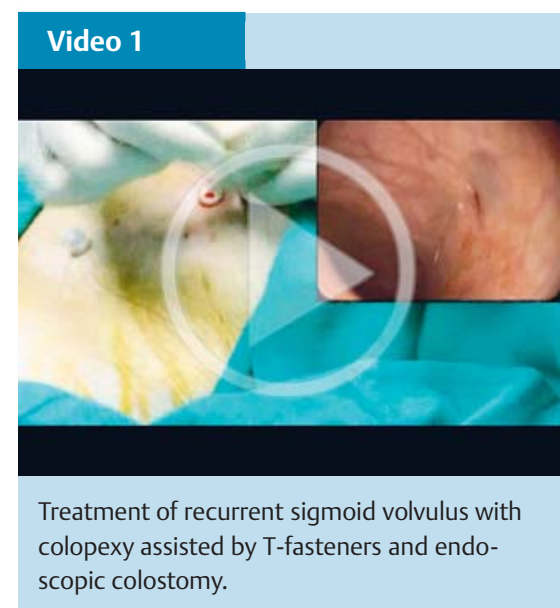

T-fasteners have been used successfully for percutaneous endoscopic sigmoidopexy [1]; however, peritonitis may develop after percutaneous endoscopic sigmoidostomy [2]. We present a patient with recurrent sigmoid volvulus who was treated endoscopically by sigmoidopexy assisted by T-fasteners and sigmoidostomy.

A 95-year-old man was hospitalized five times between July 2013 and February 2015 because of recurrent sigmoid volvulus. Surgery was not an option owing to patient co-morbidity, so a combined endoscopic approach, involving colopexy and colostomy, was proposed.

Following bowel preparation, colonoscopy was carried out in the endoscopy suite with the patient in the supine position, under deep sedation and with antibiotic prophylaxis. The colon was insufflated with air. Abdominal wall transillumination at $28 \mathrm{~cm}$ from the anal margin allowed an appropriate colopexy site to be selected from the sigmoid colon. Externally, a 21-G needle was used to ensure the appropriate

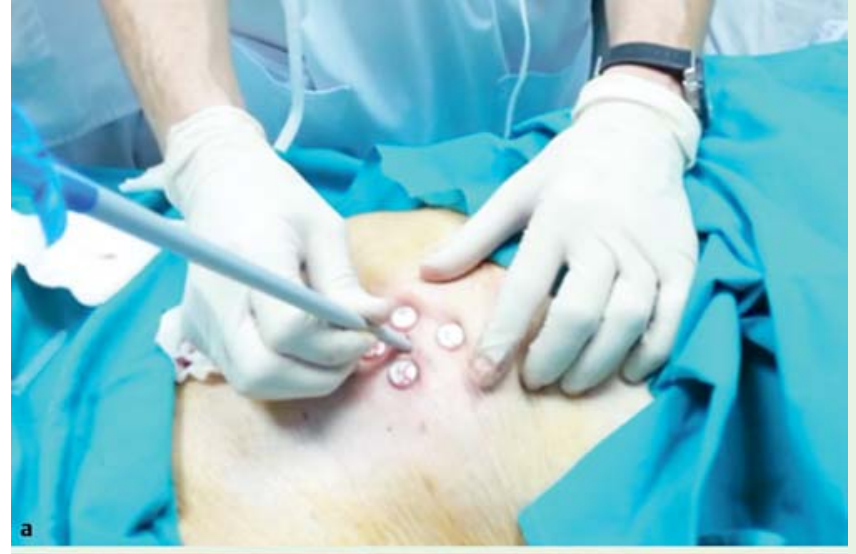

Fig. 2 Serial dilator advanced over a guidewire into the colon. a External view. b Endoscopic view.

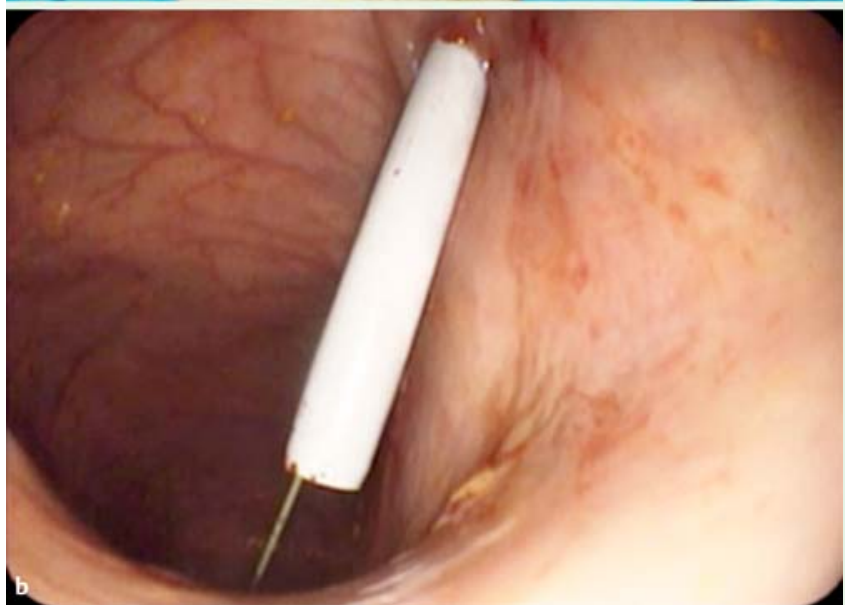

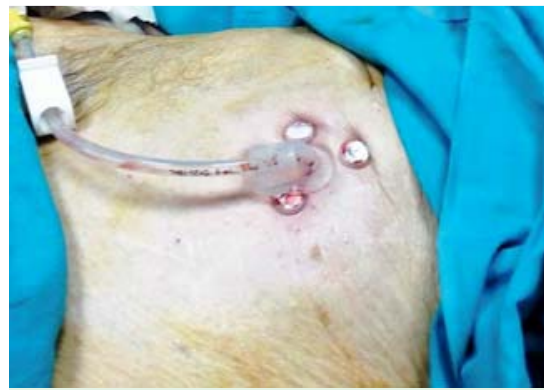

Fig.3 Percutaneous gastrostomy tube in place.

location and direction before placement of a T-fastener to fix the sigmoid colon to the abdominal wall. A total of four T-fasteners were placed in a square arrangement $(\bullet$ Fig. 1, $\bullet$ Video 1). A small incision was then made using a surgical blade, and a 19-G trocar needle and a guidewire were inserted into the colon. Progressive dilations were performed to create a stoma tract ( $\bullet$ Fig. 2). Finally, a 20-Fr gastrosto-

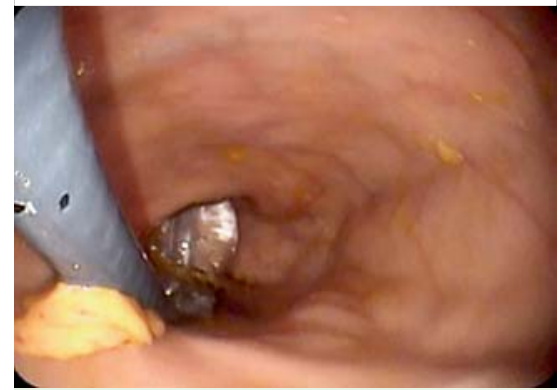

Fig.4 Endoscopic retroversion showing a colonic perforation in front of the colostomy track.

my tube was placed using the "push" technique ( $\bullet$ Fig.3). A $2-3 \mathrm{~mm}$ colonic perforation was immediately seen ( $\bullet$ Fig.4), and was closed using four clips and two endoloops ( $\bullet$ Fig.5).

The patient was discharged from hospital 2 days later. After 17 days, the suture locks released spontaneously. The patient died 10 months later from pneumonia, without recurrence of volvulus. 


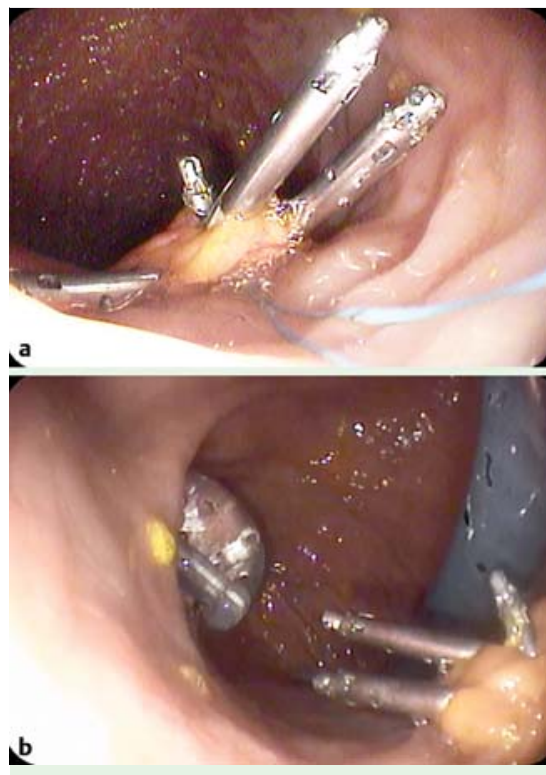

Fig. 5 The colonic perforation was closed using clips and endoloops. a Frontal view. b Retroversion view.
We conclude that the combined endoscopic colopexy assisted by T-fasteners and colostomy has potential use in the prevention of recurrent sigmoid volvulus in patients at high surgical risk. In addition, early complications may be detected immediately and treated during the same procedure. More cases are needed to establish the utility and safety of this combined approach in this setting.

Endoscopy_UCTN_Code_TTT_1AQ_2AJ

Competing interests: None

Antonio López-Serrano, Christian

A. Amurrio, Jaime Hervás, Patricia Latorre, Inmaculada Ortiz, Ana Polanco, Eduardo Moreno-Osset

Department of Gastroenterology, Hospital Universitari Dr. Peset, University of Valencia, Valencia, Spain

\section{References}

1 Pinedo G, Kirberg A. Percutaneous endoscopic sigmoidopexy in sigmoid volvulus with T-fasteners: report of two cases. Dis Colon Rectum 2001; 44: 1867-1869

2 Molina-Infante J, Fernandez-Bermejo M, Mateos-Rodriguez JM. Recurrent rectosigmoid volvulus and fatal peritonitis after percutaneous endoscopic sigmoidostomy. Endoscopy 2012; 44(Suppl. 02): E331 - 332

Bibliography

Dol http://dx.doi.org/

10.1055/s-0042-109603

Endoscopy 2016; 48: E236-E237

(c) Georg Thieme Verlag KG

Stuttgart · New York

ISSN 0013-726X

\section{Corresponding author}

\section{Antonio López-Serrano, MD}

Servicio de Medicina Digestiva Hospital Universitari Dr. Peset

Av. Gaspar Aguilar, 90

46007 Valencia

Spain

Fax: +34-96-3862501

lopez_antser@gva.es 